\title{
La entidad de los vínculos de familia según la Corte Suprema de Chile, para efectos de revocar las resoluciones de expulsión de inmigrantes ${ }^{*}$
}

\section{Alexis Mondaca Miranda**}

Resumen: En el presente trabajo se estudia la jurisprudencia de la Corte Suprema, máximo tribunal de justicia de Chile. En concreto, se analizan las sentencias recaídas sobre las acciones de amparo deducidas por los inmigrantes, con las que se intenta dejar sin efecto las medidas de expulsión que los afectan, emanadas de la autoridad administrativa. El fundamento de las acciones de amparo está constituido por el daño que la ejecución de la expulsión puede causar a los nexos familiares que han constituido.

Palabras clave: Vínculos de familia, matrimonio, uniones de hecho, filiación, inmigración, principio de proporcionalidad de las sanciones.

\section{Bonds of Family for Purposes of Revoking Orders of Expulsion of Aliens According to the Supreme Court of Justice of Chile}

Aвstract: In the present article, the jurisprudence of the Supreme Court -the highest court of justice in Chile- is studied. Specifically, rulings on petitions for

* $\quad$ Este trabajo se inscribe en el proyecto Fondecyt de Iniciación 2015 n. ${ }^{\text {o }}$ I I I 5 I I 8 ("La incidencia de los vínculos de familia en la resolución de las acciones de amparo deducidas para revocar las decisiones administrativas de expulsión de extranjeros"). Fecha de recepción: 29 de abril de 20 I 7. Fecha de aceptación: 9 de octubre de 20r7. Para citar el artículo: Mondaca Miranda, A., "La entidad de los vínculos de familia según la Corte Suprema de Chile, para efectos de revocar las resoluciones de expulsión de inmigrantes", Revista de Derecho Privado, Universidad Externado de Colombia, n. ${ }^{\circ}$ 33, enero-junio de 201 7, 237-2 50. DOI: https://doi.org/Io. I860 I/or 234366.n33.09

** Doctor en Derecho. Profesor de Derecho civil, Facultad de Ciencias Jurídicas de la Universidad Católica del Norte, Antofagasta, Chile. Contacto: amondaca@ucn.cl 
injunctive relief filed by immigrants. Said petitions seek to abrogate orders of expulsion directed at them and issued by the administrative authority. Said petitions are based on the eventual damaging of the bonds of family that may result from the enforcement of the order of removal.

KEYwords: Bond of family, marriage, unmarried couples, filiation, immigration, principle of proportionality of penalties.

\section{Introducción: el fenómeno migratorio en Chile}

Chile, desde 200 I, se ha convertido en uno de los principales destinos en América Latina en materia de inmigración ${ }^{\mathrm{I}}$. En efecto, las estadísticas demuestran que Chile ha recibido en las últimas décadas importantes flujos migratorios ${ }^{2}$. Según los datos del Instituto Nacional de Estadísticas, el crecimiento de la población extranjera es el siguiente: 83.805 (Censo I982), I05.070 (Censo I992), I84.464 (Censo 2002) y 44I.529 (Censo 20I4). Esto es, si se comparan los últimos datos con la cifra del Censo de I982, podemos concluir que se ha quintuplicado el número de extranjeros ${ }^{3}$. No se incluye en estas cifras a los inmigrantes que no han regularizado su situación de residencia; por lo tanto, la cifra total de extranjeros debe aumentarse considerablemente.

El escenario descrito ha provocado un alza en las órdenes de expulsión emanadas de la autoridad administrativa, ello en el evento de cometer el inmigrante algún ilícito, por ejemplo, el ingreso por vía no regularizada a territorio chileno, un delito penal o la simulación de un contrato de trabajo. La mencionada alza se explica porque los principales cuerpos normativos de extranjería, el Decreto Ley r.094 de 1975, Ley de Extranjería, publicado en el Diario Oficial de fecha I9 de julio de 1975 y el Decreto Supremo 597 de i984, Reglamento de Extranjería, publicado en el Diario Oficial el 24 de noviembre de $1984^{[4]}$, han establecido que de manera discrecional la autoridad administrativa resolverá sobre las expulsiones de extranjeros.

En este sentido, entre otras normas, destaca el artículo I 3 del Reglamento de Extranjería, en cuya virtud, respecto de la facultades de la administración: "estas atribuciones serán ejercidas discrecionalmente, atendiéndose, en especial, a la

I Tessada, J., Inmigración en Chile. Diagnóstico y Propuesta de Políticas, Santiago de Chile, Pontificia Universidad Católica de Chile, Panel de Políticas Públicas cep, $2013,2$.

2 Informe del Observatorio Iberoamericano sobre Movilidad, Migraciones y Desarrollo Humano, Madrid, Universidad de Comillas, 2016, 5 .

3 Tapia Ladino, M., "Frontera y migración en el norte de Chile a partir del análisis de los censos de población. Siglos XIX-Xxi", Revista de Geografía Norte Grande, n. ${ }^{\circ}$ 53, 2012 , I 77.

4 Estos textos regulan la entrada y residencia de extranjeros, egresos, reingresos, infracciones, sanciones y las atribuciones del Departamento de Extranjería y Migración, organismo que depende del Ministerio del Interior. 
conveniencia o utilidad que reporta al país la concesión de estos permisos, y a la reciprocidad internacional, previo informe, cuando corresponda, de Policía de Investigaciones de Chile". Podemos apreciar que se entrega a la administración un campo amplio de actuación, dada la presencia de conceptos jurídicos indeterminados, como "conveniencia" y "utilidad", los que deben ser precisados caso a caso, como se señala en la sentencia de la Corte Suprema, en adelante cs, Rol 7.0 8-2012, de r4 de septiembre. Con más detalle, se indicó en el considerando $3 .{ }^{\circ}$ de la sentencia del mismo tribunal Rol ro.769-2013, de 4 de noviembre, que "los conceptos en examen tienen relación con la protección de la seguridad del Estado y los cimientos de la institucionalidad, por cuanto respaldan el interés, en general, de la Nación"5. Además, siempre según el máximo sentenciador, ante la perpetración de una infracción, del transcrito precepto se desprende que la autoridad "puede" expulsar, pero no necesariamente "debe" hacerlo, Rol 4.463-20 I3, de i I de julio, considerando $4 \cdot^{\text {o }}{ }^{[6]}$.

Basándose en que la ley concede a la autoridad la facultad de decretar expulsiones, en algunas sentencias de la cs se ha resuelto que la orden de expulsión es "un acto administrativo emanado de autoridad competente, dictado en ejercicio de facultades expresas que la ley le confiere". Es decir, la decisión adoptada no podría ser ni ilegal ni arbitraria, tal como se indicó en el voto en contra de la sentencia Rol I.805-20I3, de 27 de marzo. Entendemos que deben rechazarse decisiones con un fundamento únicamente formal; por el contrario, la sentencia debe tener "una carga argumentativa superior a la meramente formal, como la expuesta en la decisión atacada, que se funda únicamente en las disposiciones legales y reglamentarias que cita”, cs Rol 9.08I-20I4, de 29 de abril7.

Esta interpretación ha sido promovida por el ente administrativo como fundamento de su decisión de expulsar ${ }^{8}$. En nuestra opinión, dicha interpretación es muy peligrosa para los derechos de los extranjeros, porque al construir la legitimidad de la orden de expulsión sobre la base de un aspecto exclusivamente formal,

5 Todas las sentencias citadas en el presente trabajo, se encuentran disponibles en el sitio del poder judicial de Chile: www.pjud.cl.

6 Mismo razonamiento se encuentra en la sentencia de la cs Rol 6.366-2013, de 3 de septiembre. En efecto, se indica en el considerando $3^{\circ}$ : "Tal diferenciación entre un deber y una facultad de expulsar es fundamental, pues la segunda deja un margen a la autoridad administrativa para ponderar otros elementos diversos a los que el propio precepto enumera y, en base a ellos, decidir si ejerce o no la facultad, en este caso, de expulsar al no nacional".

7 Lo mismo se resolvió en la sentencia de la cs Rol 88.i60-i6, de i6 de noviembre. Este camino es seguido en la sentencia Rol 3.073-2015, de 23 de febrero, en su considerando $2^{\circ}$ se indicó que la autoridad tiene discrecionalidad, siempre que su actuar se encuentre determinado previamente por una regla contenida en una norma jurídica, pero dicha discrecionalidad, como se desprende de la exégesis, entre otros, de los artículos 6 y i $9 \mathrm{~N}^{\circ} 26^{\circ}$ de la Constitución Política de la República, no puede constituir una arbitrariedad que prive, perturbe o amenace los derechos fundamentales de alguna persona".

8 Sentencia de la cs, considerando $2^{\circ}$, Rol $98 \mathrm{I}$-20I I , de I 4 de febrero. 
consistente en la atribución de competencias, complejo resulta para el inmigrante revertir la medida que lo afecta, aunque esta vulnere sus derechos.

Una vez decretada la expulsión, los afectados han buscado los medios que el ordenamiento jurídico les otorgar para solicitar, en sede judicial, la revocación de la medida que los afecta. Principalmente, han acudido a la acción de amparo, regulada en el artículo 2 I de la Constitución Política. Dicha acción procede respecto de privaciones, amenazas o perturbaciones a la libertad personal y a la seguridad individual 9 . La acción de amparo persigue que se apliquen las medidas pertinentes para poner fin a una situación de ilegalidad o arbitrariedad, como podría serlo una resolución de expulsión ${ }^{\mathrm{IO}}$. Es resuelta la mencionada acción en segunda instancia por la $\mathrm{Cs}^{\mathrm{II}}$.

Un fundamento de las aludidas acciones viene determinado por los vínculos de familia que poseen los inmigrantes: matrimonio, uniones de hecho y filiación $^{\mathrm{I} 2}$, los que poseerían la entidad necesaria para que el sentenciador, buscando la debida protección de la familia, revoque las órdenes de expulsión. En virtud de lo señalado, la resolución de expulsión sería susceptible de poder calificarse como "arbitraria", por lo que procedería acoger la acción de amparo deducida. Esta argumentación ha sido aceptada en varios juicios por la cs, según pasamos a detallar.

\section{La tutela jurídica de los vínculos familiares}

La cs y también las ca han aceptado que en la resolución de los juicios de extranjería no debe considerarse al inmigrante amenazado de expulsión como un sujeto aislado, dado que ello iría en contra de la realidad ${ }^{\mathrm{I}}$. Así, adecuado es analizar los vínculos de familia existentes, es decir, hay que ponderar la realidad familiar, por lo tanto, social del extranjero.

9 Vivanco Martínez, Á., Curso de Derecho Constitucional. Aspectos dogmáticos de la Carta Fundamental de I980, Santiago de Chile, Ediciones Universidad Católica de Chile, 2006, 326.

Hacemos presente que la legislación de extranjería contempla un medio directo para reclamar de la expulsión: el recurso de reclamación establecido en el artículo 89 de la Ley de Extranjería y en el artículo I 74 del Reglamento de Extranjería. Pero dicho recurso no es empleado por frecuencia, debido a que su plazo de interposición es de 24 horas, contadas desde la notificación de la medida de expulsión.

I I Las Cortes de Apelaciones (en adelante cA), son el tribunal competente en primera instancia.

I 2 Con todo, además de la filiación, se alegó como fundamento de la revocación de la medida de expulsión, el parentesco por consanguinidad en la línea recta, en concreto, el daño que podría generarse para la madre del solicitante, dado que este vivía con aquélla, además de ser su sustento económico, sentencia de la cs Rol 3.867-20 Io, de 8 de junio. En la sentencia Rol 3.999-20I4, de ig de febrero, el fundamento invocado fue el deseo del amparado de vivir en Chile con sus padres.

I 3 Consúltense las siguientes sentencias: cA de Santiago de Chile, Rol 72 I-20 I 5; cA de Arica, Rol 72-20 7; CA de Iquique, Rol 73-20I 5; CA de Copiapó, Rol 34I-2OI 5; CA de La Serena, Rol 4220 I y Corte de Apelaciones de Antofagasta, Rol 67-20 7 . 
La no inclusión en el razonamiento judicial de los mencionados vínculos puede conducir a resultados injustos, deben los jueces hacerse cargo de la entidad de los nexos familiares de los inmigrantes. Incluso, en ocasiones, no existe fundamento alguno de la decisión adoptada. Lo indicado sucedió en la sentencia de la cs Rol 9.098-20I4, de 29 de abril, que en dos líneas confirmó una expulsión, estableciendo lacónicamente que "Se confirma la sentencia apelada de catorce de abril de dos mil catorce, escrita de fojas 45 a 50 ”, sin señalar mayores fundamentos y sin siquiera individualizar cuáles eran los nexos de familia invocados por el extranjero ${ }^{\mathrm{I} 4}$.

La necesidad de considerar los vínculos familiares deriva tanto de exigencias jurídicas internacionales como de derecho interno. En este sentido, son varios los tratados y convenciones internacionales que tutelan los vínculos de familia. Así, la Declaración Universal de los DDHн, en su artículo I6, reconoce el derecho a "fundar una familia". Por su parte, el Pacto Internacional de Derechos Económicos, Sociales y Culturales establece en el artículo ı. I: "Se debe conceder a la familia, que es el elemento natural y fundamental de la sociedad, la más amplia protección y asistencia posibles, especialmente para su constitución y mientras sea responsable del cuidado y la educación de los hijos a su cargo".

Aplicando lo anterior, en la sentencia de la cs Rol 3.999-20I4, de I9 de febrero, en el voto de minoría del considerando $4 .^{\circ}$ que se pronunció por revocar la expulsión, se adujo como fundamento para ello, los artículos 5.I y 7.I de la Convención Americana de Derechos Humanos, y el artículo 44 de la Convención Internacional sobre la protección de los derechos de todos los trabajadores migratorios y de sus familiares.

Con respecto a la filiación, Chile ha suscrito y ratificado una serie de instrumentos internacionales de protección a los niños, entre ellas, la Convención sobre los Derechos del Niño. Según el inciso r. ${ }^{\circ}$ del artículo I 3 de esta última, en todas las medidas que adopten las instituciones públicas y privadas de bienestar social, los tribunales, las autoridades administrativas o los órganos legislativos, "una consideración primordial a que se atenderá será el interés superior del niño" ${ }^{5}$. Por lo tanto, llegado el momento de decidir sobre una expulsión, no puede hacerse caso omiso de los efectos que la misma producirá en los niños.

En armonía con lo afirmado, como se señaló en el voto de minoría de la ya mencionada sentencia de la cs Rol 9.098-20I4, debe tenerse presente "el sentido

I4 Esta sentencia es muy breve, no supera una página. Por la misma razón, ni siquiera se dividió en considerandos. Además del texto transcrito, en el resto del fallo se contempla un voto de minoría que consideró que debía revocarse la expulsión, puesto que el amparado tenía un hijo menor de edad.

I 5 Entre otros, sobre este punto véase, Barrientos, M., “¿El interés superior o inferior del niño? Aplicación jurisprudencial del artículo 42 de la Ley de Menores a la luz del Código Civil”, en Elorriaga de Bonis, Fabián (coord.), Estudios de Derecho civil VII. Fornadas Nacionales de Derecho civil. Viña del Mar, 20 I I, Thomson Santiago, Reuters Legal Publishing, 20 I 2, I I 7-I 26. 
globalizado de la vida moderna y la prevalencia que ha de darse a los derechos fundamentales de las personas". Este sendero también se recorrió en la sentencia Rol 66-2013, de 9 de enero de 2013, en la que se indicó en el considerando $3 .^{\circ}$ que: "El ejercicio legítimo de estas atribuciones exige, además del respeto a los derechos de las personas, una necesaria razonabilidad en la decisión de la autoridad". Lo mismo en la sentencia 8.397-20I7, de 2 I de marzo.

Sin perjuicio de lo anterior, el principal fundamento normativo de derecho interno de las acciones en análisis es de rango constitucional. De acuerdo a lo establecido en el inciso 2. ${ }^{\circ}$ del artículo r. ${ }^{\circ}$ de la Constitución Política, "La familia es el núcleo fundamental de la sociedad". Se agrega en el inciso final del mismo artículo que es deber del Estado proteger a la familia y "propender a su fortalecimiento".

Tengamos presente también que, en virtud de exigirlo el principio de igualdad ante la ley, consagrado en el $n .^{\circ} 2$ del artículo ig de la carta fundamental chilena, la protección estatal a la familia debe aplicarse con total independencia de la nacionalidad de sus integrantes. Es decir, se opone al texto constitucional realizar algún tipo de discriminación basada en la nacionalidad de las personas ${ }^{16}$.

Dentro de las normas de rango legal, entre otras, destaca el artículo i de la Ley n. ${ }^{\circ}$ I9.947, Nueva Ley de Matrimonio Civil, publicada en el Diario Oficial de 17 de mayo de 2004 . La norma citada, en la primera parte de su inciso I. ${ }^{\circ}$, reitera el texto constitucional al prescribir que "La familia es el núcleo fundamental de la sociedad", para luego precisar que "El matrimonio es la base principal de la familia".

Como podemos apreciar, queda claro que el ordenamiento jurídico chileno busca la protección de la familia. En consecuencia, los tribunales de justicia deben otorgar a la misma la debida tutela exigida por la Constitución y por las leyes.

No obstante lo señalado, existen sentencias que contienen un pronunciamiento consistente en una simple mención de los vínculos de familia, sin proceder a un auténtico análisis y valoración de los mismos. Lo anterior se pudo observar en la sentencia de la cs Rol 2.548-2015, de I6 de febrero, en cuyo considerando $4{ }^{\circ}$, se indicó: "Que sin perjuicio de lo anterior cabe agregar que los argumentos relativos a la protección constitucional de la familia y el interés superior del niño son improcedentes en la presente acción constitucional atendida la naturaleza de la misma". Nada más agrega la sentencia con relación a los vínculos de familia.

I6 Lo dicho se aplica salvo excepciones calificadas expresamente por el legislador; entre otras, se reserva a los chilenos el dominio de bienes raíces fronterizos, el extranjero no domiciliado no puede ser testigo del otorgamiento de un testamento, y para dedicarse a la actividad pesquera, en caso de ser el solicitante extranjero, necesita una autorización de permanencia definitiva. 


\section{La relevancia que la cs ha concedido a los vínculos de familia}

A continuación, analizaremos una tendencia que puede observarse en las sentencias de la cs de los últimos años, en cuya virtud se acepta la relevancia de primer orden que poseen los nexos familiares. Así, nos referimos a una serie de casos en que las resoluciones de expulsión de inmigrantes han sido revocadas, en sede judicial, en atención a los daños que de concretarse la expulsión se provocarían a la familia.

Lo indicado en el párrafo precedente, a propósito del matrimonio, se reconoció en considerando $4 .^{\circ}$ de la sentencia Rol 6.4I4-20I6, de 2 de febrero, al indicarse que "la amparada ha acreditado que tiene vínculo matrimonial con un nacional, conformando de ese modo una familia que también es objeto de protección por nuestra Constitución Política de la República en su artículo I ${ }^{\circ}$, elemento que igualmente debió ser ponderado por la autoridad administrativa al adoptar la decisión impugnada". En idéntico sentido se pronunció la cs en la sentencia Rol IO.I90-20I7, de 29 de $\operatorname{marzo}^{17}$.

El concubinato también ha sido considerado por la cs. En la sentencia Rol I.727-2016, de I 5 de marzo, se revocó la expulsión en atención a la existencia de una unión de hecho. Efectivamente, de acuerdo al considerando $3 .^{\circ}$, además del hecho de realizar una actividad remunerada, se tuvo en vista que la extranjera "convive con un ciudadano chileno, circunstancias que en su conjunto vuelven desproporcionada la sanción administrativa impuesta y la privan de fundamento racional y, consecuencialmente, permiten afirmar que se pone en peligro la libertad personal de la amparada por un acto arbitrario de la autoridad recurrida, lo que conlleva que la acción de interpuesta deba ser acogida".

En otro caso también fue decisiva la alegación de formar parte el inmigrante de una unión de hecho. En el considerando $4 .^{\circ}$ de la sentencia de la cs Rol i $2.356-$ 2015, de 2 de septiembre, se indicó que "para calificar los actos de autoridad que ahora se revisan, dadas las circunstancias personales y familiares del amparado [...], cabe advertir que ellos traen inevitables consecuencias en su ámbito familiar, afectando a su pareja por la posibilidad cierta de disgregar al núcleo familiar" ${ }^{8}$.

I 7 En esta sentencia, en una concisa fundamentación de una página, se indicó lo siguiente: "que el recurrente acreditó mediante los respectivos certificados de matrimonio y nacimiento, haber conformado una familia en Chile, todo ello, junto a lo razonado en el fallo de primer grado, lleva a concluir que la actual ejecución del decreto de expulsión que le afecta aparece como un acto administrativo carente de proporcionalidad y razonabilidad, lo que vuelve ilegal el mismo y justifica adoptar las medidas urgentes necesarias para poner término a esta amenaza a su libertad ambulatoria". Véanse, también, las sentencias roles 3.867-2010, 2.I 74-I3, 6.414-20 I6 y $9 \cdot 3$ I 7-20I 7.

I8 Mismos razonamientos en encuentran en las sentencias roles 98I-20II, 7.018-20I2, 66-20I3,

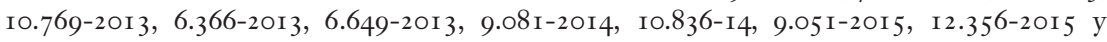
I 7.I 27-20I6. 
En concordancia con la defensa de la familia, ahora a propósito de la filiación, la cs en la sentencia Rol 9.08I-20I4, de 29 de abril, estableció en el considerando $5 .^{\circ}$, que "la ejecución de la orden de abandono del país es desproporcionada e importa una trasgresión al principio del interés superior del niño, en la especie, en relación con el menor [...] porque implicará la separación de su madre y perturbará su identidad familiar, infringiendo con ello los deberes que se imponen a los Estados en los artículos 3. I , 7. I, 8. I y 9. I de la Convención de los Derechos del Niño; y se afecta, también, lo dispuesto en el artículo I ${ }^{\circ}$ de la Constitución Política de la República que establece que la familia es el núcleo fundamental de la sociedad" 19 .

Similar sendero se recorrió en la sentencia Rol 9.05 I-20 I 5, de 22 de julio, en cuyo considerando $4 .^{\circ}$ se expresó que: "a efectos de calificar el acto de autoridad que ahora se revisa, dadas las circunstancias personales y familiares de la amparada, cabe advertir que ello trae inevitables consecuencias a la menor hija de la recurrente, de tres años, al tener un evidente apego con su madre, dada su corta edad" ${ }^{\circ}$. En breves palabras, con la expulsión se perturbaría la "identidad familiar y nacional" del menor, sentencia Rol 8.397-20I 7 de 2 I de marzo ${ }^{2}$.

Llama la atención lo establecido en el voto de minoría de la sentencia de la cs Rol I.805-I3, de 27 de marzo, puesto que en dicho caso la inmigrante, madre de un menor, no señaló la presencia de este vínculo de familia a la autoridad administrativa, pero sí lo hizo presente en sede judicial, no obstante lo cual, en razón de la aludida omisión, se entendió que no procedía apreciar la entidad del vínculo en cuestión. En efecto, se indicó que "De otra parte, la invocación que hace a la defensa a la familia, en razón de que la amparada habría concebido un hijo que nace en el territorio nacional, son razones que debió poner en conocimiento de la autoridad administrativa para que ponderara tales hechos al momento de resolver su situación migratoria, lo que no hizo, siendo ello de su propia responsabilidad". Nos parece claro que un razonamiento como el transcrito no se basa en la tutela

i9 Lo mismo se resolvió, entre otras, en las sentencias roles 3.867-2010, 7.0 I8-2012, 66-2013 y 6.366-2013.

20 Idéntico razonamiento se encuentra en el considerando $4^{\circ}$ de la sentencia de la cs Rol I 2.3562OI 5, de 2 de septiembre: "inevitables consecuencias en su ámbito familiar, afectando tanto a su pareja como a su hija, por la posibilidad cierta de disgregar al núcleo familiar, separando a la niña de uno de sus progenitores con la consecuente merma de su pleno desarrollo emocional y social. Este hecho demuestra, además, un arraigo ostensible de la familia en este país que torna la decisión de expulsión en desproporcionada y por ello arbitrario al afectar lo dispuesto en el artículo $\mathrm{I}^{\circ}$ de la Constitución Política de la República que establece que la familia es el núcleo fundamental de la sociedad, siendo deber del Estado dar protección a la población y a la familia, así como propender al fortalecimiento de ésta; derechos también consagrados en favor de los menores en la Convención de los Derechos del Niño".

2 I Sobre este vínculo de familia, véanse, también, las sentencias roles 3.867-2010, 981-201 I, 7.018-2012, г.805-2013, 2.I74-13, 66-2013, 4.463-2013, 6.366-2013, 6.649-2013, 4.466-2013, I0.769-20I3, 9.08I-20I4, 9.098-20I4, I0.836-I4, 3.574-20I5, 9.05 I-20I 5, I 2.356-20I 5, 8.397$2017,4.964-2017,9.386-$ I 7 y $9 \cdot 3$ I 7-20I 7 . 
del interés superior del niño, sino que, por el contrario, lo perjudica; en consecuencia, debe ser rechazado.

Establecida la necesidad de otorgar tutela a los vínculos de familia, debemos incluir en nuestro análisis la siguiente consideración: no basta con la mera acreditación formal de la existencia de un nexo de familia, sino que es necesario que este tenga un correlato en la realidad. Es decir, debe existir una situación efectiva de "arraigo familiar" 22 , y no debe tratarse de la creación interesada de un vínculo de familia ${ }^{23}$ con la única pretensión de obtener la nacionalidad, la residencia, un beneficio previsional ${ }^{24}$, un contrato de trabajo ${ }^{25}$ o derechamente evitar la ejecución de una resolución de expulsión.

Del mismo modo, en la sentencia de la cs Rol-62.r95-20r6, de I3 de septiembre, la falta de arraigo familiar fue el factor clave. Expresamente se indicó en el considerando 3. : "Que, a mayor abundamiento, en este procedimiento no se ha allegado ningún antecedente que dé cuenta de arraigo familiar de la amparada en este país, sino sólo el desempeño de actividad remunerada, la cual se realiza sin previamente haber regularizado su situación migratoria" ${ }^{26}$. Ha establecido

22 En este sentido, consúltese la sentencia de la cs Rol 97-599-20 16, de I 3 de diciembre.

23 Recordemos la incidencia que en el último tiempo han adquirido los llamados "matrimonios de conveniencia", es decir, los contrayentes manifiestan la voluntad de desear contraer matrimonio y de iniciar una verdadera comunidad conyugal, pero en realidad lo buscado es un beneficio en sede de extranjería. Mutatis mutandis, también podría originarse una "unión de hecho de conveniencia". Finalmente, la realidad demuestra que se han producido reconocimientos de paternidad y/o de maternidad (aunque lo último es poco frecuente), realizados con el puro fin de lograr un beneficio en sede de residencia, situación que se ha denominado "filiación de conveniencia". Sobre este punto, véase, Mondaca Miranda, A., "Reflexiones sobre uno de los desafíos que la inmigración plantea al Derecho de familia: los así denominados matrimonios de conveniencia", en Elorriaga de Bonis, Fabián (coord.), Estudios de Derecho civil IX. Fornadas Nacionales de Derecho civil, Viña del Mar, 20 I I, Santiago de Chile, Abeledo Perrot LegalPublishing, 20 I I, 4I-54. Además, véase: Audit, B., Droit international privè, 3. ${ }^{\text {a }}$ ed., París, Económica, 2000 ,

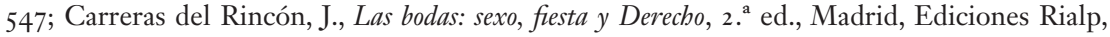
I998, i r6; Cremades García, P., "Matrimonios de complacencia: una realidad", Revista de la Facultad de Ciencias Sociales y Furídicas de Elche, vol. I, n. ${ }^{\circ}$ I, julio 2006, I3; Courbe, P., Droit de la famille, 3. ${ }^{a}$ ed., París, Armand Colin, 2003, 44; y Ragel Sánchez, L., Nulidad, separación y divorcio en la jurisprudencia, Madrid, Reus, 2003, $3 \mathrm{I}$.

24 Cea Egaña, J., Derecho constitucional chileno, $3 \cdot{ }^{a}$ ed., Santiago de Chile, Ediciones Pontificia Universidad Católica de Chile, 2015, 369-370.

25 Resulta interesante destacar que en un juicio en que el motivo de la expulsión fue la celebración de un contrato simulado, se estableció que la autoridad administrativa había formulado un reproche de carácter moral-penal específico, respecto del cual carecía de competencia, al calificar el contrato como fruto de una simulación. En efecto, en el considerando $4^{\circ}$ de la sentencia de la cs Rol 3.867-20 Io, de 8 de junio, se resolvió lo que sigue: "pero éste no ha sido acreditado como concurrente por un órgano llamado por la Constitución y las leyes para calificarlo competentemente como tal, infringiéndose de este modo los artículos 6 y 7 de la Constitución Política del Estado que consagran los principios de legalidad y juridicidad". Se agregó que la declaración de ser o no un contrato simulado implica el ejercicio de una función eminentemente jurisdiccional, función que según el artículo 76 de la Constitución Política, "corresponde a los tribunales de justicia, previo proceso legalmente tramitado".

26 Idéntico razonamiento en la sentencia de la cs Rol i 9.259-20I6, de i9 de marzo. 
la cs que el hecho de estudiar los niños en un colegio es indiciario de arraigo familiar (sentencias Rol 7.018-2012, 9.098-20I4 y I0.1756-2016) y el hecho de trabajar, de arraigo social (sentencias Rol 6.366-2013 y 4.165-2015).

En el sentido indicado precedentemente, para otorgar a la paternidad la entidad necesaria para revocar la orden de expulsión, se ha exigido demostrar la existencia de un verdadero vínculo afectivo, concretado en un contacto periódico y estable entre padre e hijo. Así, la cs en la sentencia Rol 8.080-20I7, de I3 de marzo, resolvió en el considerando $3 .^{\circ}$, "Que, si bien es cierto el amparado [...] tiene un hijo chileno, según aparece de lo informado por el Tribunal del Familia de Iquique, el año 2015 se le entregó el cuidado personal del menor a la madre y el amparado no tiene relación directa y regular con aquél”. Se añadió en el considerando $44^{\circ}:$ :Que, en consecuencia no aparece que los amparados tengan arraigo laboral, social o familiar que acrediten la existencia de un vínculo con nuestro país". En virtud de lo señalado, se revocó la sentencia de primera instancia y se confirmó la medida de expulsión.

\section{La aplicación del principio de proporcionalidad de las sanciones}

No sostenemos que la simple existencia de algún vínculo de familia impida en términos absolutos la expulsión de un extranjero, no obstante los ilícitos que pudiese haber cometido. En caso contrario, sería suficiente, por ejemplo, con iniciar una relación de concubinato para transformar en ilusoria cualquier pretensión de expulsión por parte del ente administrativo. Como hemos señalado en otra oportunidad, los nexos familiares constituyen "un aspecto que debe representarse y ponderar el sentenciador. En breves palabras, debe tomarse en cuenta la entidad e influencia de los vínculos de familia en la realidad social del extranjero expulsado y las consecuencias de su afectación; este camino conduce a una razonada y proporcional aplicación de una eventual sanción" ${ }^{27}$.

En armonía con lo señalado, es cierto que por exigencias de la lógica y de la justicia es adecuado aplicar una sanción a quien con su conducta ha violado el ordenamiento jurídico. En efecto, repugnante es dejar sin sanción al culpable de una conducta no admitida por el sistema jurídico. Existe, en consecuencia, una aparente contradicción entre, por una parte, la debida tutela de la familia, y por la otra, la necesidad de aplicar una pena a los autores de infracciones.

Esta aparente contradicción puede ser resuelta aplicando el principio de proporcionalidad de las sanciones. En conformidad a este principio, en un sen-

27 Mondaca Miranda, A., "Los nexos de familia y la revocación de las resoluciones de expulsiones de extranjeros", en Lepín Molina, C. y Gómez de la Torre Vargas, M. (coords.), Estudios de Derecho Familiar I. Actas Primeras fornadas Nacionales, Santiago de Chile, Thomson Reuters, $2016,379$. 
tido estricto, como lo han afirmado Arnold, Martínez y Zúñiga, "la gravedad de la intervención ha de ser la adecuada al objetivo de la intervención, por tanto los instrumentos y los medios aplicados deben justificarse en su grado de gravedad: la gravedad de las intervenciones debe ser proporcionada a la urgencia o necesidad de los objetivos. Si éstos no son urgentes o no son muy necesarios, los instrumentos utilizados deben ser de menor intensidad" ${ }^{28}$.

En otras palabras, una pena o sanción es desproporcionada si de ella se derivan más perjuicios que beneficios ${ }^{29}$. Aplicando lo afirmado a los litigios de expulsión, queda claro que el eventual beneficio sería la salida del territorio nacional de quien no ha respetado el ordenamiento jurídico del país que le ha acogido. Pero, por otra parte, de tener el inmigrante vínculos de familia, es posible que la afectación de estos sea de tal entidad que llegue a producir efectos negati$\operatorname{vos}^{30}$, no solo para el extranjero, sino que también para la sociedad en general. Pensemos en la disgregación de la familia, en el desarraigo que seguramente se generará. El descrito escenario empeora en el evento de existir niños, ya que a lo anterior se suma la lesión al interés superior de estos.

En el último sentido, en la sentencia Rol 4.466-2013, de i de julio, en el considerando $6 .^{\circ}$, la cs exigió ponderar "todos los antecedentes y circunstancias que parecía razonable valorar para adoptar una decisión administrativa tan trascedente para el afectado por ella, como la aquí examinada, al poner en riesgo o lesionar la libertad personal de su destinatario, rompiendo de paso con los vínculos económicos, sociales y afectivos que pueda haber desarrollado en este país". Idéntico razonamiento se encuentra en la sentencia Rol 6.649-2013, de 9 de septiembre, según su considerando $5{ }^{\circ}:$ "Que en ese orden de ideas, en el presente caso la de-

28 Arnold, R., Martínez, J. y Zúñiga, F., "El principio de proporcionalidad en la jurisprudencia del Tribunal Constitucionalidad", Estudios Constitucionales, año Iо, 20 I 2, n. ${ }^{\circ}$ I, 7 I.

29 Consúltese, también, Barnés VÁsquez, J., "Introducción al principio de proporcionalidad en el Derecho comparado y comunitario", Revista de Administración Pública, n. ${ }^{\circ}$ I 35, I 994, 500. Véase, además, Bermúdez Soto, J., "El control de la discrecionalidad administrativa", Revista de Derecho de la Universidad Católica de Valparaíso, xviı, i 996, 275-284, y Boettiger Philipps, C., "El Derecho administrativo sancionador en la jurisprudencia del Tribunal Constitucional”, Revista Actualidad Jurídica, n. ${ }^{\circ}$ 20, julio, 2009, 577-596.

Es interesante lo establecido en el voto de minoría consignado en el considerando $6^{\circ}$ de la sentencia Rol 3.999-2014, de I9 de febrero, en el que se invoca el principio pro bomine. Así, se sostuvo que este "debe informar toda decisión que debe adoptarse en asuntos como el presente, el que se traduce en que la interpretación jurídica debe siempre buscar el mayor beneficio para el ser humano, esto es, que debe acudirse a la norma más amplia o a la interpretación extensiva cuando se trata de derechos protegidos y, por el contrario, a la norma o a la interpretación más restringida cuando se trata de establecer límites a su ejercicio".

30 El no considerar la existencia de un concubinato y de hijos (la infracción cometida fue la suscripción de un contrato de trabajo simulado), permitió a la cs, en el considerando $2^{\circ}$ de la sentencia Rol 7.0I8-20I2, de I4 de septiembre, resolver que la expulsión resultó ser desproporcionada "en relación con la naturaleza, gravedad y ámbito de la infracción cometida. Ello torna en ilegal y arbitraria la decisión de revocar el permiso de permanencia definitiva de la amparada y, consecuencialmente, la orden de salida y posterior decreto de expulsión”. Revísese también, sobre este punto, la sentencia de la cs Rol 8.397-2017, de 2 I de marzo. 
cisión ministerial revisada, sin perjuicio de lo expuesto en el motivo $3^{\circ}$ ) ut supra, no satisface tampoco las exigencias de razonabilidad, proporcionalidad y fundamentación propias de una decisión no arbitraria, al desatender completamente las circunstancias personales y familiares del amparado”.

Teniendo en cuenta lo difícil que puede resultar la aplicación del principio de proporcionalidad de las sanciones ${ }^{3 \mathrm{I}}$, para facilitar dicha labor, se ha propuesto por la cs algunos criterios, tales como: realizar una actividad remunerada ${ }^{32}$; no haber cometido una infracción diversa de la que motivó la expulsión ${ }^{33}$; la obtención de beneficios carcelarios en virtud de irreprochable conducta puede revertir la orden de expulsión, como el cumplimiento de la libertad vigilada. Por el contrario, la reincidencia afectaría negativamente al inmigrante, al demostrar que el infractor se ha decidido a continuar en su vida delictiva ${ }^{34}$; y la comisión de ilícitos de particular gravedad 35 .

\section{Conclusiones}

En virtud del aumento de las expulsiones de inmigrantes, puede apreciarse en la praxis de los tribunales chilenos la deducción de acciones de amparo, fundadas en la tutela de los vínculos de familia, con las que se pretende dejar sin efecto las referidas órdenes.

Fundándose en diversos tratados y convenciones internacionales y en normas de derecho interno, junto con la defensa de los nexos familiares, se ha invocado la aplicación del principio de proporcionalidad de las sanciones. Es decir, la medida de expulsión, al provocar más perjuicios que beneficios, sería desproporcionada, lo que conduciría a su arbitrariedad; en consecuencia, a la procedencia de la revocación de la misma.

Concordamos con lo anterior. En efecto, el beneficio de la aplicación de la expulsión sería el abandono forzado del territorio nacional por parte de quien

3 I Martínez ha sostenido que la intencionalidad existente en el ilícito es un criterio relevante. Así, la presencia de dolo será más desfavorable al inmigrante que un supuesto de culpa, MArTínEz, J., "El principio de razonabilidad en la jurisprudencia del Tribunal Constitucional", Estudios Constitucionales, año 9, n. ${ }^{\circ}$ I, 201 I, I99-226.

32 Rol 4.463-2013 y IOI.756-2016.

33 Rol 4.463-20I3, 9.08I-20I4, Iо.836-I4, 4.г65-2015, 88.г6о-г6, г.727-2016, 97-599-2016, $8.397-2017$ y IO.I90-2017.

34 Roles 6.366-2013, 9.098-2014, 4.165-2015 y 10.190-201 7 .

35 Se ha resuelto que el hurto no posee la entidad necesaria para fundar la expulsión, Rol 66-20I3, de 9 de enero, lo mismo respecto del giro doloso de cheques, Rol 6.649-2013, de 9 de septiembre. A mayor detalle, en la sentencia de la cs Rol 8.080-20 I 7, de I 3 de marzo, la infracción que motivó la expulsión fue un robo con fuerza en lugar habitado, pero se mantuvo la decisión de expulsión dado que no se acreditó un vínculo afectivo real entre el amparado y su hijo. Es decir, de haberse logrado probar un correlato en la realidad del nexo de familia, se hubiese revocado la orden de expulsión. 
ha cometido algún tipo de infracción, pero la ejecución de una expulsión puede provocar la desmembración del núcleo familiar, y si existen niños, una evidente afectación al principio del interés superior de estos. Esto es, es viable que los perjuicios sean claramente superiores a los beneficios.

Con todo, con el propósito de no generar un abuso de los nexos familiares, es misión de los jueces exigir que los nombrados vínculos posean un correlato en la realidad. De esta forma, deben rechazarse las defensas basadas exclusivamente en la existencia jurídica de un nexo familiar, pero sin que tenga este una efectividad real.

En definitiva, es positivo que la cs haya tutelado, en los juicios de que hemos dado cuenta, los vínculos de familia de los inmigrantes, dado que es indesmentible la relevancia social que poseen. Al seguir este sendero, el máximo sentenciador chileno ha optado acertadamente por la preeminencia de los derechos de las personas, con independencia de su nacionalidad, por sobre un ejercicio amplio de facultades discrecionales de la administración, que no considera en su análisis la entidad de nexos tan relevantes como el matrimonio, las uniones de hecho y la filiación.

\section{Bibliografía}

Arnold, R., Martínez, J. y ZúÑIga, F., "El principio de proporcionalidad en la jurisprudencia del Tribunal Constitucional”, Estudios Constitucionales, año ı。, n. ${ }^{\circ}$ I, 20I 2, 65-II 6.

Audit, B., Droit international privè, $3 .^{\text {a }}$ ed., París, Económica, 2000.

Barnés VÁsquez, J., "Introducción al principio de proporcionalidad en el Derecho comparado y comunitario", Revista de Administración Pública, n. ${ }^{\circ}$ I 35, I $994,495-538$.

Barrientos, M., “¿El interés superior o inferior del niño? Aplicación jurisprudencial del artículo 42 de la Ley de Menores a la luz del Código Civil”, en Elorriaga de Bonis, Fabián (coord.), Estudios de Derecho civil VII. Fornadas Nacionales de Derecho civil. Viña del Mar, 20 I I, Santiago de Chile, Thomson Reuters Legal Publishing, 20 I 2, I I 7-I 26.

Bermúdez Soto, J., "El control de la discrecionalidad administrativa", Revista de Derecho de la Universidad Católica de Valparaíso, xvII, I996, 275-284.

Boettiger Philipps, C., "El Derecho administrativo sancionador en la jurisprudencia del Tribunal Constitucional”, Revista Actualidad Jurídica, n. ${ }^{\circ}$ 20, julio, 2009, 577-596. 
Carreras del Rincón, J., Las bodas: sexo, fiesta y Derecho, 2. a ed., Madrid, Ediciones Rialp, I998.

Cea Egaña, J., Derecho constitucional chileno, 3. ${ }^{\mathrm{a}}$ ed., Santiago de Chile, Ediciones Pontificia Universidad Católica de Chile, 20 I 5.

Cremades García, P., "Matrimonios de complacencia: una realidad”, Revista de la Facultad de Ciencias Sociales y Furídicas de Elche, vol. I, n. ${ }^{\circ}$ I, julio, 2006.

Courbe, P., Droit de la famille, 3. ${ }^{\mathrm{a}}$ ed., París, Armand Colin, 2003.

Martínez, J., "El principio de razonabilidad en la jurisprudencia del Tribunal Constitucional”, Estudios Constitucionales, año 9, n. ${ }^{\circ}$ I, 20 I I, I 99-226.

Mondaca Miranda, A., "Reflexiones sobre uno de los desafíos que la inmigración plantea al Derecho de familia: los así denominados matrimonios de conveniencia", en Elorriaga de Bonis, Fabián (coord.), Estudios de Derecho civil IX. Fornadas Nacionales de Derecho civil, Viña del Mar, 201 I, Santiago de Chile, Abeledo Perrot Legal Publishing, 20 I I, 4I-54.

Mondaca Miranda, A., "Los nexos de familia y la revocación de las resoluciones de expulsiones de extranjeros”, en Lepín Molina, C. y Gómez de la Torre Vargas, M. (coords.), Estudios de Derecho Familiar I. Actas Primeras Fornadas Nacionales, Santiago de Chile, Thomson Reuters, 2016, 373-388.

Ragel Sánchez, L., Nulidad, separación y divorcio en la jurisprudencia, Madrid, Reus, 2003.

Tapia Ladino, M., "Frontera y migración en el norte de Chile a partir del análisis de los censos de población. Siglos xIX-Xxi”, Revista de Geografía Norte Grande, n. ${ }^{\circ}$ 53, 2012 , I 77-198.

Tessada, J., Inmigración en Chile. Diagnóstico y Propuesta de Políticas, Santiago de Chile, Pontificia Universidad Católica de Chile, Panel de Políticas Públicas CEP, 2013 .

Vivanco Martínez, Á., Curso de Derecho Constitucional. Aspectos dogmáticos de la Carta Fundamental de I980, Santiago de Chile, Ediciones Universidad Católica de Chile, 2006. 